\title{
EXPLORING THE PROSTHODONTIC PUBLICATIONS AND AUTHORSHIP CHARACTERISTICS FROM INDIAN INSTITUTIONS IN FOUR MAJOR INTERNATIONAL PROSTHODONTIC JOURNALS- A COMPARATIVE ANALYSIS OF TEN-YEAR PERIOD
}

\author{
Anupama Aradya1, Sowmya S2, Dhakshaini M. R33, Raghavendra Swamy K. N", Ramesh Chowdhary5 \\ ${ }^{1}$ Assistant Professor, Department of Prosthodontics, JSS Dental College and Hospital, JSS Academy of Higher Education and Research, \\ Mysuru, Karnataka, India. \\ ${ }^{2}$ Assistant Professor, Department of Prosthodontics, JSS Dental College and Hospital, JSS Academy of Higher Education and Research, \\ Mysuru, Karnataka, India. \\ ${ }^{3}$ Professor, Department of Prosthodontics, JSS Dental College and Hospital, JSS Academy of Higher Education and Research, Mysuru, \\ Karnataka, India. \\ ${ }^{4}$ HOD, Department of Prosthodontics, JSS Dental College and Hospital, JSS Academy of Higher Education and Research, Mysuru, \\ Karnataka, India. \\ 5Professor, Department of Prosthodontics, Rajarajeswari Dental College and Hospital, Bangalore, Karnataka, India.
}

\section{BACKGROUND}

ABSTRACT

Over the past decade, several studies have evaluated the quantity and quality of biomedical research publications produced around the world. Specific bibliometric analyses have been conducted on published research in several biomedical fields. However, there has been limited application of the technique to assess trends in global oral health research. Global trends in prosthodontics research activity have not been evaluated.

The aim of this study was to investigate the changes in the amount, the research type of articles reported by authors from Indian institutions (Indian articles) over 10-year time span and to analyse the types of articles and authorship characteristics of Indian authors among four prosthodontics journals published in 2006 and 2015.

\section{MATERIALS AND METHODS}

This descriptive study articles published in the Journal of Prosthetic Dentistry (JPD), International Journal of Prosthodontics (IJP), Journal of Prosthodontics (JP) and Gerodontology in 2006 and 2015 were reviewed. Abstracts, Letters to the Editor and Book Reviews were not included in the investigation. The authorship characteristics included number of authors, educational qualification, academic ranks of first and last author and their geographic origin to be included. For each article, number of authors, degrees of all authors, academic ranks of first and last authors and geographic origin were recorded. Descriptive analyses was used as appropriate.

\section{RESULTS}

A total of 464 articles met the inclusion criteria from the 4 selected journals for the years studied. A total of 2 articles for the year 2006 and 17 articles for the year 2015 were published by Indian authors. It was found that $0.75 \%$ and $3.6 \%$ belonged to Indian institutes among the total publications in the year 2006 and 2015 respectively. Publications tripled in ten years from 2006 to 2015. However, in the International Journal of Prosthodontics in both years studied, no publications written by Indian authors was found. Across all 3 journals, the mean number of authors per article increased significantly from 2006 to 2015 . The mean number of authors per article increased steadily from few states of India. A steady increase of authors with higher degrees was observed. There was a significant increase in the proportion of senior-ranking faculty as last author over time. The contributions from Uttar Pradesh, Karnataka and Maharashtra increased over time.

\section{CONCLUSION}

The number of articles by Indians increased in 2015 compared to 2006. Among them, rate of original research and case reports increased in the same period, while technical reports and reviews decreased. The number of authors per article, the number of authors with higher educational degrees and the percentage of senior-ranked faculty as last authors steadily increased in the prosthodontic literature from 2006 to 2015.

\section{KEY WORDS}

Authorship, Academics, Geographic, Publications, Research.

HOW TO CITE THIS ARTICLE: Aradya A, Sowmya S, Dhakshaini MR, et al. Exploring the prosthodontic publications and authorship characteristics from Indian institutions in four major international prosthodontic journals- a comparative analysis of ten-year period. J. Evolution Med. Dent. Sci. 2018;7(44):4740-4745, DOI: 10.14260/jemds/2018/1058

'Financial or Other Competing Interest': None.

Submission 20-09-2018, Peer Review 14-10-2018,

Acceptance 20-10-2018, Published 29-10-2018.

Corresponding Author:

Dr. Anupama Aradya,

Assistant Professor,

Department of Prosthodontics, JSS Dental College and Hospital,

JSS Academy of Higher Education and Research,

Mysuru, Karnataka, India.

E-mail: dranupamavenu@gmail.com

DOI: $10.14260 /$ jemds/2018/1058

\section{BACKGROUND}

Prosthodontic research is not necessarily congruent with the field of study within which a prosthodontist earned his or her academic degree. The emerging paradigm redefines prosthodontic research as a translational science, concerned with the transformation of fundamental knowledge into treatments. The study of measures to move specific aspects of knowledge into widespread availability as quickly as possible or measures of the feasibility and utility of treatments including applicable aspects of well-being, health economics and health disparity. ${ }^{1}$ 
In recent years advances in applications, techniques and procedures have resulted in a notable increase in research. One of the main purposes of scientific articles in all fields of dentistry is to evaluate interventions and reach valid conclusions about recommended treatment modalities. With the rising number of journals worldwide, dentists showing a positive upward interest in the broader research work, the characteristics of the publications may reveal current trends. E.g. Authorship demographics, constituent components of affiliation, origin, basic or applied research and other variables. ${ }^{2}$

To assess the research contributions of countries around the world, biomedical research publication has been used as an index for health research productivity. ${ }^{3}$ Over the past decade, several studies have evaluated the quantity and quality of biomedical research publications produced around the world.4-10 Specific bibliometric analyses have been conducted on published research in several biomedical fields. ${ }^{6-10}$ However, there has been limited application of the technique to assess trends in global oral health research. ${ }^{10-12}$ Global trends in prosthodontics research activity have not been evaluated. Therefore, the purpose of this study was to evaluate the quantity and quality of prosthodontic literature produced from all the states of India in four prosthodontic journals in 2015 and comparing to publications in 2006 which gives us the comparative changes seen over the 10year period. In addition, to examine the trends in authorship in prosthodontics by-

1. Identifying the contributing factors for authorship trend;

2. Exploring the prevalence of co-authored articles;

3. Reviewing the characteristics of authorship in the prosthodontic journals including the educational degree and academic rank of authors.

\section{MATERIALS AND METHODS}

A descriptive study hand search of 4 peer-reviewed prosthodontic journals were performed for articles published in 2006 and 2015 in Indian Institutions. This period was chosen, because they represent a 10 -year observation time for the analysis of prosthodontics publications from India.

\section{Selection of Journals}

The journals selected were based on published impact factors and they are most representative of the specialty and of the prosthodontic organisations. Selected journals were-

1. Journal of Prosthetic Dentistry (JPD).

2. Journal of Prosthodontics (JP).

3. International Journal of Prosthodontics.

4. Gerodontology.

\section{Selection of Period and the Articles Type}

Evaluated time periods were from January 2006 to December 2006 and from January 2015 to December 2015. Abstracts, Letters to the Editor and Book Reviews were not included. Classification by research type with method reported as by Kanavakis et al. ${ }^{12}$ After modification namely- [1] Technical report; [2] Case report; [3] Original research; and [4] Review was used.

\section{Parameters}

For each of the included articles specific parameters collected were number of authors, educational degrees of all authors, academic ranks of first, last and remaining authors, and geographic origin of the article. With respect to number of authors based on Rosenzweig et al, the articles were grouped as having 1, 2, 3, 4, 5, 6 or more authors. The categories of the educational degrees of all authors BDS, MDS and PhD and others (MBA, MD, M Tech and MSc) were considered.

The academic ranks of first and last authors were classified as student/ resident, junior faculty, senior faculty or other/ unidentified and the classification of academic ranks was according to Drenth with modification. Classifications were simplified from the proposed 8 categories namely Instructor, Lecturer and Assistant Professor were grouped as Junior Faculty, whereas Associate Professor, Professor and Administrative Heads were classified as Senior Faculty. The geographic origin of the article was categorised by states: Karnataka, Andhra Pradesh, Tamilnadu, Uttar Pradesh, Gujarat, Rajasthan, New Delhi, Jammu and Kashmir. If more than one geographic origin of the study was listed, the state of the corresponding author was selected.

Data were recorded and coded into a software database (Microsoft Excel 2003).

\section{RESULTS}

A total of 464 articles met the inclusion criteria from the 4 selected journals for the year 2015 and 395 articles for the year 2006 studied. Table I shows the changes in the number of total articles by time in relation to journals and research type. In the year 2006 of the 395 articles published 255 articles were original research, 55 case reports, 41 reviews and 44 technical reports, and in the year 2015 of the 464 articles published 307 articles were original research, 91 case reports, 34 reviews and 32 technical reports.

The number of articles included from each journal varied by year. In the year 2006, $52.9 \%$ of the articles were from JPD, $24.5 \%$ were from IJP, $13.6 \%$ were from JP and $8.86 \%$ were from Gerodontology. In the year 2015, 49.5\% of the articles were from JPD, 18.5\% were from IJP, 22.1\% were from JP and 9.6\% were from Gerodontology. Overall for a tenyear period, publication showed a rise of $17.25 \%$, in which research publications increased to $20.39 \%$ and the case reports increased by $65 \%$, but the reviews decreased by $21 \%$ and technical reports decreased by $22 \%$.

Table II shows the changes in the number of Indian articles by time in relation to journals and research type. A total of 17 articles for the year 2015 and 2 articles for the year 2006 were published by Indian authors. This was $0.75 \%$ of the total publications for the year 2006 and 3.6\% for the year 2015. The publications tripled in ten years from 2006 to 2015. During the 10 years, there was no publication in International Journal of Prosthodontics from Indian Institutions. Even though there were less publications in the year 2006, the number of publications has increased since 10 years.

Table III shows the proportion of academic ranks of First (F) and Last (L) authors over time in India. Across all 3 journals, the number of authors per article increased significantly in 2006 to 2015. Journal of Prosthetic Dentistry had a greater number of authors than Journal of Prosthodontics and Gerodontology.

With regard to geographic origins, the number of authors per article increased steadily from 2006 to 2015. There was a 
significant difference in the number of authors per article among some states of India in 2006 and 2015. The proportion of authors from Uttar Pradesh was higher compared to all other states in 2015. In 2006, only authors from Karnataka and Tamilnadu had published articles. The proportion of single-author articles were none over time for all journals. Publications with two or three authors increased three-fold and four times from 2006 to 2015. The proportion of fourauthor articles were more (47\%) over time for all journals (Table 6 and Table 7).

Among all first authors, there was difference in the proportion of academic ranks over the years and across the journals. In contrast, there was a significant five-fold increase in the proportion of junior ranking faculty as first author over time. In contrast, the percentage of senior-ranking faculty as last author was more than $50 \%$ over time periods measured. $21 \%$ of the last authors were of other degrees like (MBA, MD, M Tech and MSc) (Fig. 3).

Among the first and last authors, over this time period a steady increase in authors with higher educational degrees was observed. Across all journals, $0.76 \%$ of the authors held both dental and $\mathrm{PhD}$ degrees in 2015. Authors holding both dental and PhD degrees were none in 2006 and it was increased to one author over time. For first, last and other authorship, from 2006 to 2015 there was increase in MDS degrees holding authors. There was $11 \%$ increase in first authors with BDS degree (Fig. 4).

The distribution of publications by states and educational degrees of all authors over the reported years is presented in Table VII. The authors holding a PhD degree were none for other states, except New Delhi in 2015. Of authors holding MDS as highest degree hailing from Uttar Pradesh increased from 2006 to 2015. In these journals in 2006 only Karnataka and Tamilnadu authors published the articles and in 2015 there was major contribution from Uttar Pradesh followed by Karnataka, Maharashtra, New Delhi, Orissa and Goa authors. There was equal contribution from Rajasthan, Punjab and Jammu and Kashmir.

\begin{tabular}{|c|c|c|c|c|c|c|c|c|c|c|}
\hline & \multicolumn{2}{|c|}{ JPD } & \multicolumn{2}{c|}{ IJP } & \multicolumn{3}{c|}{ JP } & \multicolumn{2}{c|}{ Gerodontology } & \multicolumn{2}{c|}{ Total } \\
\cline { 2 - 11 } & $\mathbf{2 0 0 6}$ & $\mathbf{2 0 1 5}$ & $\mathbf{2 0 0 6}$ & $\mathbf{2 0 1 5}$ & $\mathbf{2 0 0 6}$ & $\mathbf{2 0 1 5}$ & $\mathbf{2 0 0 6}$ & $\mathbf{2 0 1 5}$ & $\mathbf{2 0 0 6}$ & $\mathbf{2 0 1 5}$ \\
\hline Technical Report & 0 & 3 & 0 & 0 & 0 & 0 & 0 & 0 & 0 & 3 \\
\hline Case Report & 0 & 4 & 0 & 0 & 0 & 3 & 0 & 0 & 0 & 7 \\
\hline Original Research & 1 & 1 & 0 & 0 & 0 & 4 & 0 & 2 & 1 & 7 \\
\hline Review & 0 & 0 & 0 & 0 & 0 & 0 & 1 & 0 & 1 & 0 \\
\hline Total
\end{tabular}

\begin{tabular}{|c|c|c|c|c|c|c|c|c|c|c|}
\hline & \multicolumn{2}{|c|}{ JPD } & \multicolumn{2}{|c|}{ IJP } & \multicolumn{3}{c|}{ JP } & \multicolumn{2}{c|}{ Gerodontology } & \multicolumn{2}{c|}{ Total } \\
\cline { 2 - 13 } & $\mathbf{2 0 0 6}$ & $\mathbf{2 0 1 5}$ & $\mathbf{2 0 0 6}$ & $\mathbf{2 0 1 5}$ & $\mathbf{2 0 0 6}$ & $\mathbf{2 0 1 5}$ & $\mathbf{2 0 0 6}$ & $\mathbf{2 0 1 5}$ & $\mathbf{2 0 0 6}$ & $\mathbf{2 0 1 5}$ \\
\hline Technical Report & 35 & 29 & 3 & 1 & 6 & 4 & 0 & 0 & 44 & 34 \\
\hline Case Report & 39 & 46 & 8 & 14 & 6 & 25 & 2 & 6 & 55 & 91 \\
\hline Original Research & 121 & 142 & 75 & 62 & 28 & 70 & 31 & 33 & 255 & 307 \\
\hline Review & 14 & 13 & 11 & 9 & 14 & 4 & 2 & 6 & 41 & 32 \\
\hline Total & $\mathbf{2 0 9}$ & $\mathbf{2 3 0}$ & $\mathbf{9 7}$ & $\mathbf{8 6}$ & $\mathbf{5 4}$ & $\mathbf{1 0 3}$ & $\mathbf{3 5}$ & $\mathbf{4 5}$ & $\mathbf{3 9 5}$ & $\mathbf{4 6 4}$ \\
\hline
\end{tabular}

Table 2. Changes in the Amount of Total Articles by Time in relation to Journals, Research Type

\begin{tabular}{|c|c|c|c|c|}
\hline \multirow{2}{*}{} & \multicolumn{2}{|c|}{$\mathbf{2 0 0 6}$} & \multicolumn{2}{c|}{2015} \\
\cline { 2 - 5 } & First Author & Last Author & First Author & 8 \\
\hline Senior Faculty & 1 & 0 & 3 & 2 \\
\hline Junior Faculty & 0 & 0 & 10 & 1 \\
\hline Student/ Resident & 0 & 0 & 3 & 4 \\
\hline Other & 0 & 0 & 1 & 4 \\
\hline No Info & 1 & 2 & 2 & \\
\hline \multicolumn{2}{r}{ Table 3. Proportion of Academic Ranks of First (F) and Last (L) Authors over time in India } \\
\hline
\end{tabular}

\begin{tabular}{|c|c|c|}
\hline \multirow{2}{*}{ Author Numbers } & \multicolumn{2}{|c|}{ Number of Publications } \\
\cline { 2 - 3 } & $\mathbf{2 0 1 5}$ & 0 \\
\hline 1 & 0 & 1 \\
\hline 2 & 3 & 1 \\
\hline 3 & 4 & 0 \\
\hline 4 & 9 & 0 \\
\hline 5 & 2 & 0 \\
\hline 6 & 0 & 0 \\
\hline 7 & 1 & \\
\hline Table 4. Prevalence of Published Articles having 1, 2, 3, 4 and 5 or More Authors Per Article over time in India \\
\hline
\end{tabular}




\begin{tabular}{|c|c|c|c|c|c|c|}
\hline \multirow{2}{*}{ Degrees } & \multicolumn{2}{|c|}{ First Author } & \multicolumn{2}{c|}{ Last Author } & \multicolumn{2}{c|}{ All } \\
\cline { 2 - 7 } & $\mathbf{2 0 1 5}$ & $\mathbf{2 0 0 6}$ & $\mathbf{2 0 1 5}$ & $\mathbf{2 0 0 6}$ & $\mathbf{2 0 1 5}$ & $\mathbf{2 0 0 6}$ \\
\hline BDS & 2 & 0 & 1 & 0 & 28 & 1 \\
\hline MDS & 14 & 2 & 11 & 2 & 1 & 0 \\
\hline PhD & 0 & 0 & 0 & 0 & 5 & 0 \\
\hline Others (MBA, M Tech, MD, MSC) & 1 & 0 & 5 & 0 & \multicolumn{2}{|c|}{0} \\
\hline No Info & \multicolumn{2}{|c|}{0} \\
\hline
\end{tabular}

\begin{tabular}{|c|c|c|c|c|c|c|c|c|c|c|}
\hline Year & Karnataka & Tamilnadu & Maharashtra & $\begin{array}{c}\text { Uttar } \\
\text { Pradesh }\end{array}$ & Orissa & $\begin{array}{c}\text { New } \\
\text { Delhi }\end{array}$ & Punjab & Goa & Jand K & $\begin{array}{c}\text { Madhya } \\
\text { Pradesh }\end{array}$ \\
\hline 2006 & 1 & 1 & 0 & 0 & 0 & 0 & 0 & 0 & 0 & 0 \\
\hline 2015 & 3 & 0 & 3 & 9 & 1 & 2 & 0 & 1 & 0 & 0 \\
\hline \multicolumn{7}{|l|}{ Journal } \\
\hline JPD & 0 & 1 & 2 & 5 & 0 & 1 & 0 & 0 & 0 & 0 \\
\hline JP & 2 & 0 & 1 & 3 & 1 & 1 & 0 & 1 & 0 & 0 \\
\hline IJP & 0 & 0 & 0 & 0 & 0 & 0 & 0 & 0 & 0 & 0 \\
\hline Gerodontology & 2 & 0 & 0 & 1 & 0 & 0 & 0 & 0 & 0 & 0 \\
\hline
\end{tabular}

Table 6. Number of Published Articles and their Geographic Origin by Year and by Journal in India

\begin{tabular}{|c|c|c|c|c|c|c|c|c|c|c|}
\hline Year & \multicolumn{9}{|c|}{ 2006 } & \multicolumn{5}{c|}{ 2015 } \\
\hline Geographic Origin & BDS & MDS & Ph D & Other & No Info & BDS & MDS & Ph D & Other & No Info \\
\hline Karnataka & 0 & 3 & 0 & 0 & 0 & 0 & 8 & 0 & 2 & 0 \\
\hline Tamilnadu & 0 & 2 & 0 & 0 & 0 & 0 & 0 & 0 & 0 & 0 \\
\hline Maharashtra & 0 & 0 & 0 & 0 & 0 & 0 & 7 & 0 & 1 & 0 \\
\hline Orissa & 0 & 0 & 0 & 0 & 0 & 0 & 4 & 0 & 1 & 0 \\
\hline Uttar Pradesh & 0 & 0 & 0 & 0 & 0 & 4 & 27 & 0 & 4 & 0 \\
\hline New Delhi & 0 & 0 & 0 & 0 & 0 & 0 & 5 & 1 & 2 & 0 \\
\hline Punjab & 0 & 0 & 0 & 0 & 0 & 1 & 0 & 0 & 0 & 0 \\
\hline Rajasthan & 0 & 0 & 0 & 0 & 0 & 0 & 0 & 0 & 1 & 0 \\
\hline Goa & 0 & 0 & 0 & 0 & 0 & 1 & 2 & 0 & 0 & 0 \\
\hline Jammu and Kashmir & 0 & 0 & 0 & 0 & 0 & 0 & 1 & 0 & 0 & 0 \\
\hline \multicolumn{7}{|c|}{ Table 7. Authors'Educational Degrees by Year, Journal and Geographic Origin in India } \\
\hline
\end{tabular}

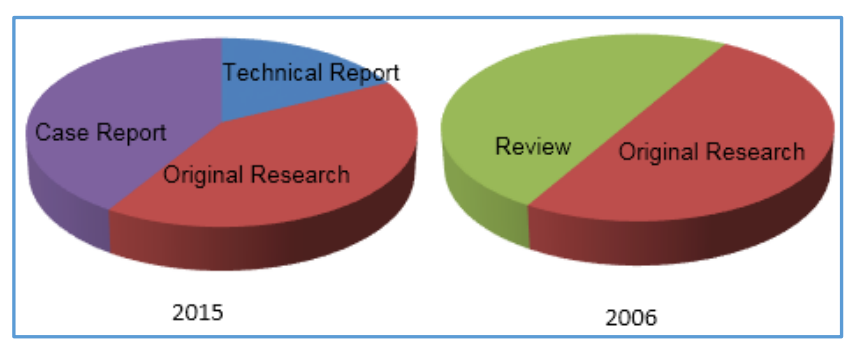

Figure 1. Changes in Percentage of Publications in Indian Articles

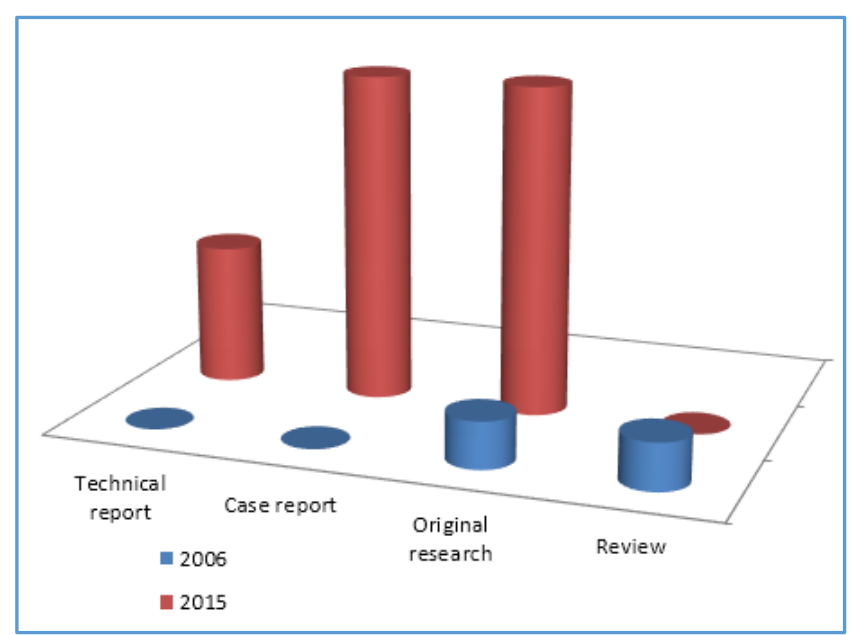

Figure 2. Changes in Percentage of Indian Articles out of Total Articles by Research Type during 10 Years

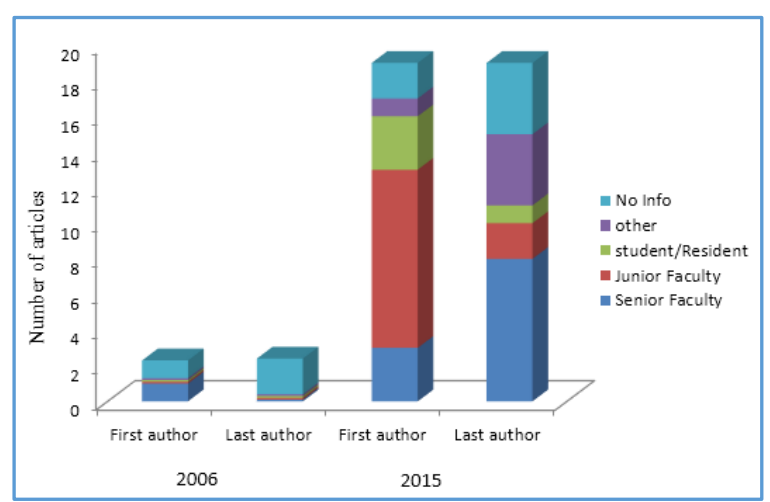

Figure 3. Proportion of Academic Ranks of First (F) and Last (L) Authors Over Time

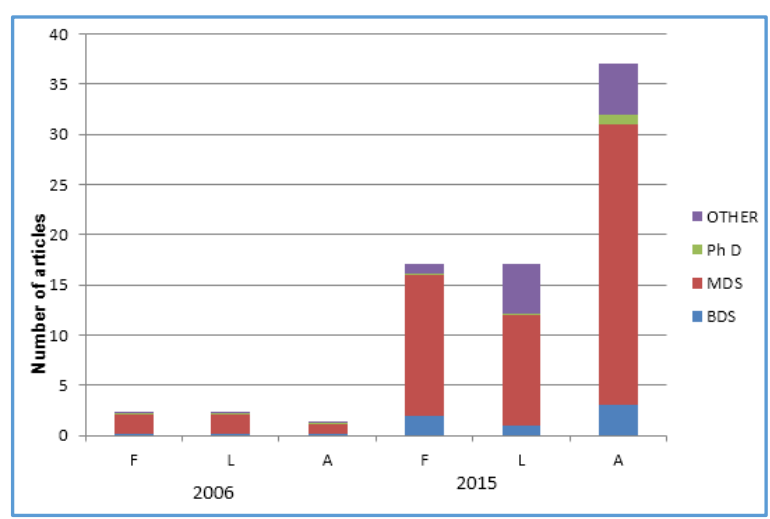

Figure 4. Proportion of Educational Degrees of First (F), Last (L) and All (A) Authors Over Time 


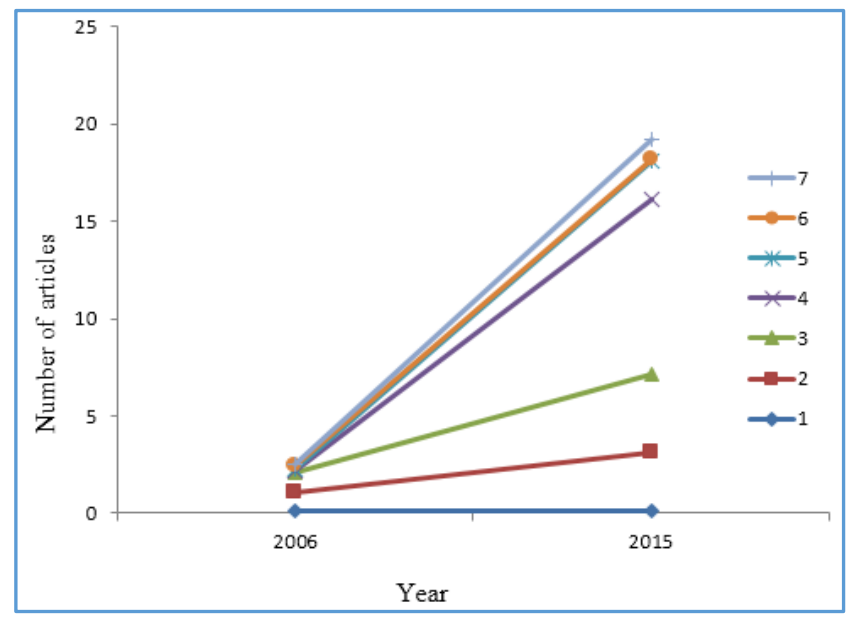

Figure 5. Prevalence of Published Articles having 1, 2, 3, 4 and 5 or More Authors per Article Over Time

\section{DISCUSSION}

The present study includes a longitudinal set-up comparing four major prosthodontics journals over a period of 10 years. Comparing the contribution from Indian authors, it appears that the publications have almost increased 8.5 times the number of papers in the four journals analysed in 2006 and in 2015 year (Fig. 2).

The Journal of Prosthetic Dentistry and Journal of Prosthodontics Journals were showing a significant increase in publications by the Indian authors from 2006 to 2015. At the same time, the percentage of case reports and original research articles have increased in the JPD and JP by the Indian authors, but in International Journal of Prosthodontics there were no contribution from Indian authors in both the years. Whereas, overall the Case Reports and Original Research Publications were increased in all the 4 journals, but in the Gerodontology Journal the review numbers were also increased in this interval. In other three journals like JPD, JP, IJP showed decrease in number of Review and Technical Report publications. Faculties were more concerned on Original Research Work.

This study demonstrated that multiple authorship has become more prevalent in the prosthodontic literature. The number of authors per article increased significantly over time (Fig. 1). In contrast, the proportion of articles by a single author has decreased dramatically over time. These trends are similar to previous trends reported for the medical literature. ${ }^{12-23}$

Tables 6 and 7 show that Uttar Pradesh was the main contributor to this increase. Articles from other states were likewise increased. On the other hand, fewer articles from Karnataka state were published in both 2006 and 2015 years. These results are in accordance with the findings of a bibliometric study on prosthodontics literature. The present study also revealed an increasing number of authors.

In comparison with non-academic centres and nonprosthodontics units, academic prosthodontic departments contributed to the publications to a higher extent. This might reflect the fact that specialty educational programs have enhanced their research programs because of an increased competitiveness in attracting research grants as a means of financial security as well as employment of prosthodontic faculty with substantial research background.24
The proliferation of authorship has been documented since the 1930 s. ${ }^{14}$ Weeks et al ${ }^{19}$ found the average number of authors per article increased from 4.5 in 1980 to 6.9 in 2000 in 4 medical journals. Podolsky et al ${ }^{16}$ noted an increase in the number of authors per article from 1.1 in 1972 to 2.6 in 1981. Others have reported a steady increase in the proportion of articles with 6 or more authors. $14,17,19,20$

In the present study a steady increase in authors with higher educational degrees was observed, while an increase in senior ranked faculty and a great surge in dental and $\mathrm{PhD}$ degrees for last authorship were noted. This observation may confirm a trend shown in previous studies ${ }^{13,18}$ that seniorranking faculty now usually hold higher educational degrees. In addition with more faculty obtaining advanced training, it could be construed that there is more proficiency and interest in performing research. This observation may indicate a promising future for the specialty.

This may also indicate that individuals who have achieved academic stature are still capable of publication, because they have established themselves and thereby continue to receive the funding that ensures their future as investigators. In contrast, younger faculty members may have less time to participate in research due to heavier teaching loads. Few younger faculty members may be provided with adequate dedicated time for research investigations.

In the current study, it was observed that the contributions from Uttar Pradesh, Karnataka and Maharashtra had a multi-fold increase and this mirrors the trends in Internationalisation in the medical literature. ${ }^{12,14,25,26}$ Publications from the rest of the globe represent the positive impact that prosthodontics has on the advancement of knowledge. Diverse contributions to the literature, broadened readership and International collaboration are outcomes of increased globalisation which may be measured through the impact factors and reputations of journals. ${ }^{14,26,27}$

The current study has identified some notable findings regarding geographic origin and its association with authorship. Author from New Delhi has demonstrated an increasing trend in dual degrees (Dental and $\mathrm{PhD}$ degrees). It may be speculated that more authors have received advanced research training and education over the years; thus, more authors with advanced degrees are emerging in publications. The contributions from Uttar Pradesh had a higher number of authors per article compared to other states over the same period. This could be due to the nature of the article, complexity of the research or culture of authorship. ${ }^{19}$ The publications with four authors were more followed by three authors and five authors publications (Table 4, Fig. 5).

One of the limitations in this study was that this result was obtained from four sample journals and two sample periods. There may be publication bias because of selection of only four journals (JPD, JP, IJP and Gerodontology). For the more exact conclusion, further research that includes more sample articles and sample periods are required.

\section{CONCLUSION}

The number of Indian articles increased in 2015 compared to the number in 2006. The rate of Original Research and Case Report increased in the same period, while technical reports and reviews decreased. This demonstrates the current scenario, which shows the upward trend in quality and quantity of publications. 
Within the Limitations of this Study, the following Conclusions were drawn-

1. The number of authors per article in the prosthodontic literature has steadily increased from 2006 to 2015.

2. The number of authors with higher educational degrees has increased, especially from Uttar Pradesh, Karnataka, New Delhi and Maharashtra.

3. The percentage of senior-ranking faculty as last author was higher and has increased $42 \%$ over time.

\section{REFERENCES}

[1] Stohler CS. Prosthodontic research: breaking traditional barriers. J Can Dent Assoc 2005;71(5):332.

[2] Baumgartner S, Pandis N, Eliades T. Exploring the publications in three major orthodontic journals: a comparative analysis of two 5-year periods. Angle Orthod 2014;84(3):397-403.

[3] Rahman M, Fukui T. Biomedical publication-global profile and trend. Public Health 2003;117(4):274-80.

[4] Soteriades ES, Rosmarakis ES, Paraschakis K, et al. Research contribution of different world regions in the top 50 biomedical journals (1995-2002). FASEB J 2006;20(1):29-34.

[5] Falagas ME, Michalopoulos AS, Bliziotis IA. A bibliometric analysis by geographic area of published research in several biomedical fields, 1995-2003. CMAJ 2006;175(11):1389-90.

[6] Michalopoulos A, Bliziotis IA, Rizos M, et al. Worldwide research productivity in critical care medicine. Crit Care 2005;9(3):R258-R65.

[7] Michalopoulos A, Falagas ME. A bibliometric analysis of global research production in respiratory medicine. Chest 2005;128(6):3993-8.

[8] Rosmarakis ES, Vergidis PI, Soteriades ES, et al. Estimates of global production in cardiovascular diseases research. Int J Cardiol 2005;100(3):443-9.

[9] Tas F. The contribution of countries and world regions in productivity of oncological publication. Ann Oncol 2008;19(11):1962-8.

[10] Gil-Montoya JA, Navarrete-Cortes J, Pulgar R, et al. World dental research production: an ISI database approach (1999-2003). Eur J Oral Sci 2006;114(2):102-8.

[11] Robert C, Caillieux N, Wilson CS, et al. World orofacial pain research production: a bibliometric study (20042005). J Orofac Pain 2008;22(3):181-9.

[12] Kanavakis G, Spinos P, Polychronopoulou A, et al. Orthodontic journals with impact factors in perspective: trends in the types of articles and authorship characteristics. Am J Orthod Dentofacial Orthop 2006;130(4):516-22.

[13] Drenth JP. Multiple authorship: the contribution of senior authors. JAMA 1998;280(3):219-21.
[14] Modi P, Hassan A, Teng CJ, et al. How many cardiac surgeons does it take to write a research article? Seventy years of authorship proliferation and internationalization in the cardiothoracic surgical literature. J Thorac Cardiovasc Surg 2008;136(1):4-6.

[15] Papatheodorou SI, Trikalinos TA, Ioannidis JP. Inflated numbers of authors over time have not been just due to increasing research complexity. J Clin Epidemiol 2008;61(6):546-51.

[16] Podolsky SM, Gold I, Kuhn M, et al. Research topics, author's specialty and funding sources of articles published in an emergency medicine journal. Ann Emerg Med 1984;13(6):429-31.

[17] Rosenzweig JS, Van Deusen SK, Okpara 0, et al. Authorship, collaboration and predictors of extramural funding in the emergency medicine literature. Am J Emerg Med 2008;26(1):5-9.

[18] Shulkin DJ, Goin JE, Rennie D. Patterns of authorship among chairmen of departments of medicine. Acad Med 1993;68(9):688-92.

[19] Weeks WB, Wallace AE, Kimberly BC. Changes in authorship patterns in prestigious US medical journals. Soc Sci Med 2004;59(9):1949-54.

[20] Shaban S, Aw TC. Trend towards multiple authorship in occupational medicine journals. J Occup Med Toxicol 2009; 4:3.

[21] Shapiro DW, Wenger NS, Shapiro MF. The contributions of authors to multiauthored biomedical research papers. JAMA 1994;271(6):438-42.

[22] Figg WD, Dunn L, Liewehr DJ, et al. Scientific collaboration results in higher citation rates of published articles. Pharmacotherapy 2006;26(6):75967.

[23] Shamim T. The point system of the Dental Council of India for publications by faculty. Natl Med J India 2016;29(5):312.

[24] Matson ML, Matso JL, Lott JD, et al. Representation of international authorship across prominent journals in the field of mental retardation. Res Dev Disabil 2002;23(4):293-6.

[25] Cappell MS, Davis M. A significant decline in the American domination of research in gastroenterology with increasing globalization from 1980 to 2005: an analysis of American authorship among 8, 251 articles. Am J Gastroenterol 2008;103(5):1065-74.

[26] Durani P, Rimouche S, Ross G. How many plastic surgeons does it take to write a research article? Authorship proliferation in and internationalisation of the plastic surgery literature. J Plast Reconstr Aesthet Surg 2007;60(8):956-7.

[27] Yuan JC, Lee DJ, Knoernschild KL, et al. Authorship characteristics in prosthodontics literature: proliferation and internationalization. A review and analysis following a 10-year observation. J Prosthet Dent 2010;104(3):158-64. 